\title{
Opening a Pandora's Box: \\ Proper Names in English Phraseology
}

\author{
Patrizia Pierini (Rome)
}

\begin{abstract}
This article explores the linguistic-cultural aspects and usage of phraseological units involving personal and place names in English. The introductory sections outline the linguistic features of proper names and phraseological units. The qualitative part of this study provides a list of units belonging to four phraseological types (idioms, stereotyped similes, binomials, formulae), drawn from idiom dictionaries. An investigation of the sources of names shows that the personal and place names involved are historically, socially or culturally prominent in British culture. Here is noted a predominance of personal over place names, and within the former, a predominance of male over female names, and first names over family names, with a number of hypocorisms. The quantitative part of the study consists of a corpus search of the selected units in the British National Corpus in order to find their frequency and distribution across registers. The search reveals that they have very low levels of occurrence, and are more commonly used in written registers, in particular, in fiction, journalism and miscellaneous texts.
\end{abstract}

\section{$1 \quad$ Introduction}

Naming a single entity is one of the basic speech acts, included by Searle (1975) in the class of declaratives, alongside declaring war, dismissing and bequeathing. People and places, pets and hurricanes, rock groups and festivities, institutions and commercial products, works of art and shops are given a name (Lehrer 1994). Naming serves to highlight entities that play a role in people's daily life, and to establish and maintain an individuality in society.

Object of analysis of onomastics, proper names (henceforth PNs) have been investigated by philosophers, logicians, anthropologists and psychologists, but only sporadically by linguists: e.g. with different approaches and concerns, Sloat (1969), Molino (1982), Allerton (1987), Marmaridou (1989), Gary-Prieur (1991), Hough (2000), Tse (2004), Anderson (2007).

From an overview of the literature on this area of language, it emerges that special attention has been paid to theoretical issues, while investigations on specific aspects in individual languages are infrequent. This article is concerned with PNs in English phraseology. If we examine idioms, the dominant subtype of phraseological units, we observe that they involve elements regarded as relevant for various reasons: body parts, because human beings as natural (and cultural) entities are at the centre of language; natural elements, animals, colours, clothing and food, because they are salient aspects of everyday life; references to the Bible, because it is culturally relevant in Anglo-Saxon society. So, we expect to find a number of PNs because of their great importance in human communication, where they are signs of cultural, linguistic, geographical, ethnic and social identity. Their analysis can offer an insight into the interplay between language and culture in phraseology. 
This paper aiming to explore the linguistic-cultural aspects and usage of phraseological units containing personal and place names (the major PN subcategories), is organised as follows. Section 2 and 3 outline the linguistic features of PNs and phraseological expressions, respectively. Section 4 provides a list of units belonging to four types (idioms, stereotyped similes, binomials, formulae), drawn from idiom dictionaries. Section 5 looks at what personal and place names are involved in the expressions. Section 6 discusses the results of a search for the collected units in the British National Corpus aimed at establishing their frequency and distribution across registers. Section 7 presents the concluding remarks.

\section{Proper Names in Language}

It is generally agreed among linguists (Hockett 1958: 311-313) that PNs are a universal linguistic category. Their status and function is a theoretical issue debated by many scholars, whose views are discussed in Carroll (1983), Coates (2006) and Van Langendonck (2007: 6-118). The topic is complex and controversial, and the account given will be brief and schematic; this means that some aspects will not be considered.

PNs constitute a system organised according to criteria varying across cultures, and provide an interpretation of the society of which they are the expression. They are linguistic items fulfilling a referential function, i. e. they refer to single entities existing in the real world ${ }^{1}$ (Lyons 1977: 214-223). Like deictics, they enable primary identification of their referents; but, unlike deictics, they are not dependent on the immediate situational context (Molino 1982: 19; Lyons 1977: 214; Van Langendonck 2007: 169-71). Like nouns, PNs constitute an open class of words and, hence, are lexical rather than grammatical; but, unlike nouns, they lack lexical meaning.

Let us now survey the main linguistic features of PNs in English (Van Langendonck 2007: 93-106, 119-182; Anderson 2007). Their first feature is the initial-capitalisation in writing, whose function is to distinguish a PN from a common noun, e.g. Rosemary vs. rosemary. They are subject to some word formation processes: for example, hypocorisms can be formed from full first names, employing various mechanisms (Anderson 2003: 371), as illustrated in (1):

$\begin{array}{lll}\text { FULL FORM } & \text { HYPOCORISM } & \\ \text { John } & \text { Johnny } & \text { (suffixation) } \\ \text { Joseph } & \text { Joe } & \text { (shortening) } \\ \text { Richard } & \text { Dick } & \text { (shortening and phonological modification) }\end{array}$

With regard to grammar, names raise various issues. One issue concerns the internal structure of names (Anderson 2003; Tse 2004): they can be mono- or polylexemic, sometimes incorporating the article (e.g. London, John Smith, The Dead Sea); personal names can be preceded by a title (e.g. Mr Smith, Aunt Mary), whose status is rather controversial.

A major issue is represented by the different uses of names. In their primary use as referring expressions, PNs can occupy the NP slot, as in (2a-b), but can also function as vocatives, as in $(2 \mathrm{c})$, and occur in close appositional structures, as in $(2 \mathrm{~d})$ :

(2) (a) He loves Mary.

(b) They live in Oxford.

(c) I read that, Walter.

(d) The poet Tennyson died early.

\footnotetext{
${ }^{1}$ With regard to PNs denoting fictitious entities, such as Santa Claus or Leopold Bloom, they can be described as items referring to entities that 'exist' in the discursive world.
} 


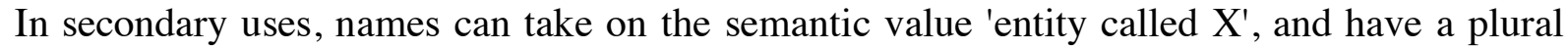
form, as in (3):

(3) There are few Alfreds in the class.

They can occur with determiners: the article the or a/an, as in (4 a-b); quantifiers, as in (4c); possessives, as in (4d); demonstratives, as in (4e):

(a) I haven't been in touch with the Joneses for ages.

(b) I've never met an Ophelia.

(c) I know three Ann Smiths.

(d) My Jennifer has won the school prize again.

(e) Who's this Penelope who's been sending you emails?

They can be modified by adjectives, restrictive relative clauses or PPs, as in (5), (6), (7), respectively:

(5) He's the famous George.

(6) This is the Paris I prefer to forget.

(7) The London of my childhood was different.

To account for these data, analysts distinguish between the grammatical category 'proper name' having the syntactic status of NP, assigned to the names in (2), and the category 'proper noun', having the status of common noun, assigned to the names in (3)-(7).

Let us now consider the semantics of PNs, an issue much discussed from Mill (1867) onwards. They are diachronically motivated, and a meaningful etymon is found in most cases: e.g. family names derive from elements of common vocabulary referring to parentage (son of Richard $>$ Richardson), or occupation (miller $>$ Miller). But they are synchronically opaque; as stated by Lyons (1977: 198), "it is widely, though not universally, accepted that proper names do not have sense".

Provided that they are elements fulfilling a referential function, how the relation between PN and referent is established can be explained pragmatically. A PN is assigned to a given referent by some social convention ${ }^{2}$, and encyclopaedic information is associated with it in long-term memory (Marmaridou 1989: 355-56). In particular, personal names may be attributed to more than one referent, yet, in discourse the encoder refers to a specific referent, situated in a given time and space. In order to understand which referent the encoder is referring to, the decoder must possess a competence of the name system as well as the chunks of encyclopaedic knowledge associated with a name to establish a link between PN and referent. Only when the decoder retrieves associated information from his/her knowledge, the 'virtual' referent is actualised, and the PN becomes a 'rigid designator' (a notion introduced by Kripke, 1972). Let us now consider (8):

(8) He saw Philip on the street corner.

The decoder recognises Philip as a PN, but does not possess the chunk necessary to pair PN and referent. Yet, names can arouse expectations based on encyclopaedic knowledge; so Philip is expected to be the first name of a 'male human being'. Hence the decoder interprets the name as 'male human being', but it might refer to a dog.

In short, PNs constitute a class of linguistic items sharing features with both nouns and deictics. Formally, PNs share some grammatical features with common nouns, but differ from them in various respects. Both PNs and deictics lack lexical meaning and have a referential

\footnotetext{
2 See, for example, the 'baptismal act' in Kripke (1972: 298-302), and the 'performative nomination' in Lyons (1977: 217-218).
} 
function; but, while the interpretation of deictics depends on the situational context, the interpretation of PNs depends on the linguistic context and encyclopaedic knowledge. In interpreting the PN, the decoder first has to recognise whether its use is referential or figurative, relying on the linguistic context ${ }^{3}$; then, s/he will activate encyclopaedic knowledge or recur to her/his lexical competence, if the item is lexicalised (see below). Finally, PNs refer to a 'fixed' referent, while deictics to a referent that can vary according to the situational context.

Another use of names is central to understand the phenomenon under discussion. PNs, in particular personal names, more rarely place names, are used figuratively as metaphors, similes, hyperboles and antonomasias, either in a creative way (e.g. He is a new Hemingway) or as lexicalised items. In these uses, PNs have a descriptive function: they indicate some salient attribute or property of the referent of the name. They function as nouns, taking on both a denotational and a connotational meaning originated in a selection of salient bits of information extracted from encyclopaedic knowledge about a referent. Consider the examples in (9):

(a) She is playing Pollyanna.

(b) The war is becoming a Vietnam.

In (9a), Pollyanna, referring to the chief character in the novel Pollyanna (1913) by E. Porter, denotes a person constantly or excessively optimistic. In (9b), Vietnam, referring to the country where US troops intervened, takes on the meaning 'disastrous military intervention'.

The metaphorical use of PNs reflects cultural specificities (Wee 2006) that can pose problems in translation (Pierini 2006). As we shall see in the next sections, names show their more complex properties and their culture-specific features in phraseology. Since it abounds in cultural information, Russian scholars argue that linguo-cultural analysis is best suited for this area of language (Teliya et al. 1998).

\section{$3 \quad$ Phraseology and phraseological units}

The term 'phraseology' originated in Russian studies which developed from the late 1940's to the 1960's (Cowie 1998: 4). It is now currently used to refer either to the set of phraseological units in a language, or to the branch of linguistics studying them. Scholars have provided various definitions of these units and various criteria to classify them (Fernando 1996: 3-22; Moon 1998: 19-25; Gläser 1998). My working definition is the following: a phraseological expression is a sequence constituted by at least two independent lexical items, stored as a unit in lexis. Its basic features, as mentioned in the literature, are: a) fixedness ${ }^{4}-$ it is a multiword unit, fixed in syntax as well as lexis; b) institutionalisation - it is a conventionalised unit, being the result of an initially novel expression; c) non-compositionality - its global meaning is not predictable from the meaning of its constituent words.

Phraseological expressions often carry connotations not present in their non-idiomatic synonimic expressions, and can have various functions in discourse: the informational, the evaluative, the situational, the modalising and the organisational function (Moon 1998: 217-240). When classifying them, a useful distinction is that suggested by Gläser (1998: 126-127), between word-like and sentence-like expressions. Word-like units designate a

\footnotetext{
3 The linguistic context is also relevant when the PN refers to more than one entity: Paris can refer to the capital of France, a city in Texas, or the Trojan prince; its referent can be identified by interpreting the linguistic context.

${ }^{4}$ In fact, various studies (e.g. Fernando 1996: 42-56; Gläser 1998: 129-30; Grant 2005: 439-44), have shown that fixedness is not absolute: systemic, geographical or creative variations on canonical forms can be observed in discourse, concerning grammatical and/or lexical form.
} 
phenomenon, an object, an action, a process or state, a property in the real world; they embrace idioms and non-idioms (i.e. restricted collocations), functioning as nouns, verbs, adjectives or adverbs. Sentence-like units, such as proverbs, maxims and formulae, designate a whole state of affairs in the real world. The transition area between the two groups is occupied by units such as irreversible binomials, stereotyped similes, and fragments of proverbs.

My analysis is focused on four phraseological types of which I am now going to give a short description. The first type is the 'idiom', a word group having the structure of : a noun phrase (e.g. a hot potato); a verb phrase (e.g. bark up the wrong tree); an adjective phrase (e.g. wet to the skin), a prepositional phrase (e.g. beyond compare), or an adverb phrase (by far). The second type is the 'irreversible binomial' (Gläser 1998: 126; Moon 1998: 152-156), a pair of two words belonging to a same part of speech joined by and, and occurring in a fixed order (e.g. odds and ends).

The third type is the 'stereotyped simile' (Moon 1998: 150-152), occurring in two structures. The first, typically occurring in predicative position, is $($ as $)+\mathrm{Adj}+a s+\mathrm{NP}$ (e.g. blind as a bat). The adjective, quite ordinary and gradable in most cases, is used literally, and the NP, used figuratively, serves to intensify the meaning of the adjective. The nouns in NP are entities (humans, animals, objects) to which British people have conventionally attributed certain characteristics, the same characteristic expressed by the adjective. Over time, each NP has come to represent the epitome of individual characteristics. The other structure is $\mathrm{V}+$ like $+\mathrm{NP}$ (e.g. eat like a horse), where the verb is used literally and the NP figuratively, to intensify the meaning of the verb. The fourth type is the 'formula' (Gläser 1998: 127; Moon 1998: 21f.), a situation-based expression serving a specific discursive function, typically occurring in spoken discourse (e.g. Good luck; It's a small world).

\section{$4 \quad$ Compiling a List of Phraseological Units}

By surveying four idiom dictionaries (CCDI, LDEI, LID, ODI), I collected a total of 91 expressions, selecting the units labelled as 'British' or without any geographical label: 69 idioms, 5 binomials, 11 similes and 6 formulae. For each unit, I provided usage labels, when found in dictionaries ('derogatory', 'euphemistic', 'humorous', 'colloquial/informal', 'formal', 'dated', 'old-fashioned', 'archaic', 'slang', 'literary'). The manner of arrangement chosen to present the list of data is by phraseological type and syntactic structure.

\subsection{Idioms I: Noun Phrases}

Idiomatic noun phrases can have various structures. The first type is the sequence (Det) + PN:
(a) Joe Bloggs
(b) a Florence Nightingale
(c) a Walter Mitty

The second type is the sequence (Det) + title + PN:
(a) a Colonel Blimp
(b) a Mrs Grundy
(derog)
(c) Aunt Sally
(d) Uncle Sam
(e) Uncle Tom Cobley and all
(inf) 
The third type is constituted by sequences involving Det, Adj and PN in various combinations, except for (12k):

$\begin{array}{lll}\text { (12) } & \text { (a) } & \text { an admirable Crichton } \\ \text { (b) } & \text { a doubting Thomas } & \\ \text { (c) } & \text { an honest Joe } & \text { (coll) } \\ \text { (d) } & \text { a nosey Parker } & \text { (inf) } \\ \text { (e) } & \text { the old Adam } & \text { (old-fash) } \\ \text { (f) } & \text { a peeping Tom } & \\ \text { (g) } & \text { a plain Jane } & \\ \text { (h) } & \text { sweet Fanny Adams } & \text { (euph) } \\ \text { (i) } & \text { the real McCoy } & \text { (inf) } \\ \text { (j) } & \text { every Tom, Dick and Harry / } \\ & \text { any Tom, Dick or Harry/Harriet (inf) } \\ \text { (k) } & \text { every man Jack } & \text { (inf) } \\ \text { (l) } & \text { the new Jerusalem } & \text { (lit) }\end{array}$

The next type is represented by more complex phrases:

$($ Det $)+\mathrm{PN}^{\prime} s+\mathrm{N}$
(a) Achilles' heel
(b) Adam's ale
(c) an Aladdin's cave
(d) a Benjamin's portion
(e) a Frankenstein's monster
(f) Hobson's choice
(g) a Job's comforter
(h) Morton's fork
(i) Nessus' shirt /shirt of Nessus (lit)
(j) Tom Tiddler's ground

Det $+\mathrm{PN}+\mathrm{N}$

(14) (a) a Judas kiss

(b) a London particular

(c) the Midas touch

(d) The Queensberry rules

(e) a Potemkin village

$\mathrm{NP} 1+$ preposition $+\mathrm{NP} 2$ (the name can be in NP1 or NP2)
(a) Alice in Wonderland
(inf)
(b) a Jack of all trades (and master of none) (coll)
(c) a labour of Hercules
(d) the man on the Clapham omnibus
(e) the mark of Cain
(f) a sword of Damocles

\subsection{Idioms II: Verb Phrases}

In this group, idioms are presented in two separate lists, whether involving a personal or a place name. The name can occur in object NP, or in PP:

(16) (a) appeal from Philip drunk to Philip sober

(b) appeal to Caesar

(c) give a Roland for an Oliver (archaic)

(d) go to Davy Jones's locker

(e) keep up with the Joneses 
(f) live the life of Riley (inf)

(g) not know someone from Adam (inf)

(h) open (a) Pandora's box

(i) out-Herod Herod

(j) raise Cain

(k) rob Peter to pay Paul

(l) take the Mickey (out of) (inf)

(17) (a) build castles in Spain

(b) carry/take coals to Newcastle (inf)

(c) fiddle while Rome burns

(d) have kissed the Blarney Stone (inf)

(e) meet one's Waterloo

(f) paint the Forth Bridge

(g) pile/heap Pelion on Ossa

(h) send someone to Coventry (inf)

\subsection{Idioms III: Prepositional Phrases}

In this type (prep + NP), the name occurs in NP.

(18) (a) according to Hoyle

(b) in Abraham's bosom (dated, euph)

(c) on one's Jack (slang)

(19) (a) between Scylla and Charybdis (lit)

(b) (not) for all the tea in China (coll, hum)

(c) from China to Peru (lit, old-fash)

(d) in Queer Street (inf, dated)

\subsection{Idioms IV: subordinate clause}

(20) before one/you can say Jack Robinson (inf)

\subsection{Irreversible binomials}

The binomials selected consist of $\mathrm{PN}+$ and $+\mathrm{PN}$, except for (21e) consisting of $\mathrm{Adj}+$ and + Adj (a compound containing a PN):

(21) (a) David and Goliath

(b) Damon and Pythias

(c) Darby and Joan

(hum)

(d) Jekyll and Hyde

(e) shipshape and Bristol fashion

\subsection{Stereotyped similes}

The similes having the structure (as) Adj $+a s+\mathrm{NP}$ (initial as is generally optional) are shown in (22), and V + like + NP in (23):

(22) (a) happy as Larry

(b) hot as Hades

(c) old as Adam

(d) pleased as Punch

(e) poor as Lazarus

(dated)

(f) rich as Croesus

(23) (a) be like Hamlet without the prince

(b) be like the Black Hole of Calcutta

(c) feel like Daniel in the lion's den 
(d) fight like Kilkenny cats (dated)

(e) grin/smile like a Cheshire cat (coll)

\subsection{Formulae}

These expressions appear as a phrase or a clause. Their status as pragmatically specialised units is, in most cases, focused on in dictionaries, where the method of defining them is 'context-based': the lexicographic definitions, quoted in (24a-f), express in what context and for what discursive purpose each formula is used:
(a) (and) Bob's your uncle
(b) I'm all right, Jack
(c) for the love of Mike
(d) it's even Stephen

(e) (it's) Murphy's law

(f) all Lombard Street to a China orange (inf) 'everything is fine, problem solved' (ODI)

(inf) 'used to express or comment upon selfish complacency' (ODI)

(inf) 'used to accompany an exasperated request or to express dismay' (ODI)

(coll) 'it is a situation in which all the persons concerned have an equal chance of finally winning or succeeding' (LDEI)

(coll) 'used in order to say that the worst possible thing always seems to happen when it is most annoying' (LID)

(inf) 'used in the context of making a bet, either explicitly or implicitly' (ODI)

\subsection{On the list}

Two points need to be remarked. One idiom containing a name was excluded: A 1 at Lloyd's, because the PN is a trade name. The units (10) and (11) in section 4.1 above are of different nature: (10a) has an unknown origin; $(10 \mathrm{~b}-\mathrm{c})$ and $(11 \mathrm{a}-\mathrm{b})$ are lexicalised eponyms. In addition, the names in (10) are just a few from a large number of units in use: for example, making a cursory check of the general-purpose CED, we find John Bull, Jack Frost, Joe Soap, Tommy Atkins, among others; some are typical of a national variety, e.g. John Hancock, used in American English. So, my selection reflects lexicographic information. The two-word units in (10) and (11) were considered on the grounds of the working definition of phraseological expression given in section 3 above: a sequence of two independent items that has taken on a figurative meaning.

With regard to phraseological types, the most numerous group of expressions is constituted by idiomatic noun phrases (41 units). With regard to their context of use, most are informal, some are fairly literary. As to their function in discourse, formulae have a situational function in that each is related to a specific context. Some of the other types convey information (e.g. not know someone from Adam); most express evaluation, for example, by intensifying qualities (rich as Croesus) or processes (grin like a Cheshire cat). As pointed out by Moon (1998: 244-45), evaluation may be centred on the encoder, who projects his/her personal judgement, as in Jack of all trades. Or, it may be centred on the culture at large, projecting collective norms of good and bad, as in Judas kiss. But the distinction is often difficult since a unit can encode both the speaker's opinion and a reference to shared values or norms, as in honest Joe. Many expressions convey a negative evaluation of people's character or behaviour, as in Colonel Blimp and fiddle while Rome burns. In discourse, they seem to operate as politeness devices or euphemisms, expressing disapproval or criticism indirectly. 


\section{$5 \quad$ Sources and uses of PNs}

Considering the names in phraseological expressions, we can note a predominance of personal over place names (unsurprisingly, given the anthropocentricity of language); within the former, a predominance of male over female names, and first names over family names, with a number of hypocorisms. The very low presence of female names is motivated by sociocultural factors: in society, men played (and still play) a more active role than women. Among them, we find: Alice in Wonderland, Florence Nightingale, Mrs. Grundy, Aunt Sally, plain Jane, Pandora, (Darby and) Joan, Fanny Adams. They are usually employed to convey a negative or not wholly positive evaluation.

With regard to the presence of hypocorisms derived from very common first names (Bob, Dick, Harry, Joe, Jack, Larry, Mike, Mickey, Tom), it seems to be a culture-specific feature of English phraseology; for example, hypocorisms are rarely found in Italian phraseology. In particular, Mike and Mickey are now the generic name for an Irishman; Jack has come to denote any individual person, and also occurs in compounds, denoting types of person (e.g. Jack-in-office, jack-the-lad), objects (e.g. Jack-in-the-box, Jack-a-Lent, Jack-o-lantern), plants (Jack-in-the-pulpit) and animals (jackdaw).

An overview of the personal names involved in the expressions indicate the following types of sources:

- the Bible: doubting Thomas; Judas kiss; the mark of Cain; David and Goliath; like Daniel in the lion's den; old as Adam;

- literary texts: internationally known works (Aladdin's cave from The Arabian Nights); famous British works, by Shakespeare (be like Hamlet without the prince), Stevenson (Jekyll and Hide), Carroll (Alice in Wonderland), Mary Shelley (Frankenstein's monster); more marginal works, by James Thurber (Walter Mitty), and Tom Morton (Mrs Grundy);

- classical heritage, i. e. mythology and figures of Greek and Roman antiquity: Pandora's box; Achilles' heel, Nessus' shirt, Midas touch, rich as Croesus, Damon and Pythias; appeal to Caesar;

- popular culture: Darby and Joan (after a couple mentioned in an $18^{\text {th }}$-century ballad); pleased as Punch (after Mr. Punch, from the traditional children's puppet show 'Punch and Judy'); Colonel Blimp (after a character in newspaper cartoons created by David Lowe in the late 1930s); Aunt Sally (referring to the figure of an old woman's head, used in fairgrounds and fêtes as a target for balls or other objects); Tom Tiddler's ground (a children's game); Uncle Tom Cobley and all (Uncle Tom Cobley is the last of a long list of men in the English song "Widdicombe Fair", c. 1800);

- real people, rarely legendary figures: Florence Nightingale (after the famous nurse (18201910) who served in military hospitals during the Crimean War); Hobson's choice (after Thomas Hobson (1544-1631), a livery man who gave his customers no choice, but made them take the nearest horse); peeping Tom (after the tailor that, according to legend, peeped at Lady Godiva when she rode naked through Coventry); Morton's fork (after John Morton (1420-1500), who was Archbishop of Canterbury and chief minister of Henry VII; the expression refers to the argument used by Morton to extract loans); the Queensberry rules (after Sir John Sholto Douglas, Marquis of Queensberry, who drew up a code of rules to govern boxing in 1869); according to Hoyle (after Edmond Hoyle (1672-1769), barrister and writer of works on card games); sweet Fanny Adams (after the 8-year-old victim in a famous murder case in 1867; it is often abbreviated in speech to sweet $F A$, which is vulgarly understood to be a euphemism for the taboo phrase fuck all); happy as Larry (probably after the famous Australian boxer Larry Foley (1847-1917)); a Potemkin village 
(after Count Potemkin (1739-1791) who ordered a number of sham villages to be built for the Empress Catherine II's tour of Crimea).

In some cases, the source of the PN is unknown (live the life of Riley, Murphy's law). In one case, the PN is not actually a name: Uncle Sam is apparently a humorous interpretation of the letters stamped on army supply boxes during the War of 1812, i. e. U.S.

The collected expressions exemplify the two mechanisms exploited in the use of PNs in phraseology: on one hand, the use of very common names (e.g. keep up with the Joneses, where Jones, one of the most frequent family names, is used as a generic name for one's neighbours); on the other hand, the 'cultural allusion', i. e. the reference to people and places the members of British culture are (or were) familiar with. In this case, denotational (and connotational) meaning is established extracting salient bits of information from world knowledge associated with each of them.

Also the examination of place names reveals interesting aspects. They refer to:

- places in UK: London, with its fog and districts (a London particular, from Dickens's Bleak House; the man on the Clapham omnibus); Newcastle-upon-Tyne, which was a centre of coal-mining (carry coals to Newcastle); Coventry, probably from an old story that soldiers on military duty there were greatly disliked by the people of the town (send to Coventry); Bristol, a major port trading with America in the $17^{\text {th }}$ and $18^{\text {th }}$ century, hence the reference to ships newly painted, with scrubbed surfaces and brass polished (shipshape and Bristol fashion); the Cheshire county (grin like a Cheshire cat, after the character in Carroll's Alice in Wonderland); the Irish town of Kilkenny (fight like Kilkenny cats); Blarney Stone near Cork (have kissed the Blarney Stone); the Forth Bridge in Scotland (paint the Forth Bridge);

- eastern countries related to the British colonial past: India, in like the Black Hole of Calcutta, referring to an event in Calcutta in 1756, when a large number of Europeans were put into one very small prison for a night; in the morning, only a few were still alive; China, in all Lombard Street to a China orange, (not) for all the tea in China, from China to Peru;

- places related to classical heritage: fiddle while Rome burns; between Scylla and Charybdis;

- places on the Continent: Spain (build castles in Spain), and Waterloo (meet one's Waterloo).

\section{The corpus search}

The collected expressions were searched for in the British National Corpus ${ }^{5}$ to find their frequency and distribution across registers. I opted for this corpus for several reasons: its status of reference tool for British English; its size (it amounts to some 100 million words, 90 million written, and 10 million spoken); its range and representativeness (it is made up of various types of written texts - literary, journalistic, academic, and miscellaneous texts - and spoken texts - conversations, lectures, business meetings, TV/radio broadcasting, speeches); the availability of an interface on the Internet that allows to search for phrases by register.

Since many expressions may undergo modifications in discourse (as many $40 \%$, according to Moon 1998: 120), care was taken that the corpus search found all occurrences of a given unit, including any variation in: hyphenation (Jekyll and Hyde / Jekyll-and-Hyde); reduction (open a Pandora's box / a Pandora's box); lexical form (carry/take coals to Newcastle); inflection (the various verb forms in VPs); grammatical form (meet his/her/their Waterloo, Achilles' heel / Achilles heel).

\footnotetext{
5 Accessed via the interface available at http://corpus.byu.edu/BNC.
} 
The following Tables 1-7 show the search results correlating phraseological type with frequency distribution. Variations in units are signalled by bracketing the element not found in all occurrences, e.g. (carry/take) coal $(s)$ to Newcastle. The units are presented in the form in which they occur in the corpus: e.g. while dictionaries register it's even Stephen, Table 7 presents it was even Steven. The registers considered are: S (spoken), F (fiction), N (news), A (academic) and $\mathrm{M}$ (miscellaneous) ${ }^{6}$. Some quantitative data in Table 1 were obtained manually to distinguish the figurative use of the name from its referential use (e.g. Uncle Sam, Florence Nightingale, Alice in Wonderland).

\begin{tabular}{|c|c|c|c|c|c|c|}
\hline NP & $\mathbf{S}$ & $\mathbf{F}$ & $\mathbf{N}$ & $\mathbf{A}$ & M & Total \\
\hline Achilles' heel / Achilles heel & 3 & 3 & 15 & 4 & 26 & 51 \\
\hline an Aladdin's cave & 2 & 10 & 5 & 1 & 26 & 44 \\
\hline a peeping Tom & 1 & 13 & 2 & 3 & 10 & 29 \\
\hline Uncle Sam & - & - & 9 & - & 16 & 25 \\
\hline a Frankenstein('s) monster & - & 11 & - & - & 11 & 22 \\
\hline the Midas touch & 1 & 1 & 9 & - & 10 & 21 \\
\hline Tom, Dick and /or Harry & - & 6 & 2 & 1 & 7 & 16 \\
\hline Aunt Sally & - & 5 & 1 & 1 & 9 & 16 \\
\hline a sword of Damocles & 2 & 1 & 3 & 1 & 9 & 16 \\
\hline a Jack of all trades & 2 & - & 3 & 1 & 9 & 15 \\
\hline the real McCoy & 3 & 1 & 3 & - & 7 & 14 \\
\hline a Walter Mitty & 1 & - & 7 & - & 5 & 13 \\
\hline the man on the Clapham omnibus & 1 & 1 & 1 & 1 & 8 & 12 \\
\hline Joe Bloggs & 4 & - & - & 5 & 1 & 10 \\
\hline a plain Jane & 1 & 2 & - & - & 7 & 10 \\
\hline Hobson's choice & - & - & 3 & 1 & 6 & 10 \\
\hline a labour of Hercules & - & 2 & 1 & - & 7 & 10 \\
\hline a nosey Parker & 1 & 4 & 2 & - & 2 & 9 \\
\hline the old Adam & - & 4 & 1 & 3 & 1 & 9 \\
\hline the Queensberry rules & - & 2 & 3 & - & 4 & 9 \\
\hline Alice in Wonderland & 1 & 1 & 1 & - & 5 & 8 \\
\hline a doubting Thomas & - & 2 & - & - & 5 & 7 \\
\hline the new Jerusalem & - & 4 & - & - & 3 & 7 \\
\hline a Florence Nightingale & 1 & 2 & - & - & 1 & 4 \\
\hline Uncle Tom Cobley and all & - & - & 1 & - & 2 & 3 \\
\hline sweet Fanny Adams & - & - & - & - & 3 & 3 \\
\hline Morton's fork & - & - & - & 3 & - & 3 \\
\hline the mark of Cain & - & 2 & - & - & 1 & 3 \\
\hline a Colonel Blimp & - & - & - & 2 & - & 2 \\
\hline every man Jack & - & 2 & - & - & - & 2 \\
\hline shirt of Nessus & - & - & - & 2 & - & 2 \\
\hline a Judas kiss & - & - & 1 & - & 1 & 2 \\
\hline
\end{tabular}

${ }^{6}$ Under M I grouped two registers distinct in the interface, i.e. Non-fictional miscellaneous and Other miscellaneous. 


\begin{tabular}{|l|c|c|c|c|c|c|}
\hline a London particular & 1 & 1 & - & - & - & 2 \\
\hline an honest Joe & - & 1 & - & - & - & 1 \\
\hline a Job's comforter & - & - & - & 1 & - & 1 \\
\hline a Potemkin village & - & - & - & - & 1 & 1 \\
\hline a Mrs Grundy & & & & & & 0 \\
\hline an admirable Crichton & & & & & & 0 \\
\hline Adam's ale & & & & & & 0 \\
\hline a Benjamin's portion & & & & & & 0 \\
\hline Tom Tiddler's ground & & & & & & 0 \\
\hline
\end{tabular}

Table 1. Frequency distribution of idiomatic NPs (from highest to lowest number of occurrences)

\begin{tabular}{|l|c|c|c|c|c|c|}
\hline VP & S & F & N & A & M & Total \\
\hline take the Mickey & 15 & 5 & 12 & 2 & 15 & 49 \\
\hline (open (up) a) Pandora's box & - & 11 & 3 & 6 & 17 & 37 \\
\hline rob Peter to pay Paul & 7 & - & 2 & 1 & 5 & 15 \\
\hline not know someone from Adam & 2 & 6 & - & - & 2 & 10 \\
\hline (carry/take) coal(s) to Newcastle & 1 & 2 & 3 & - & 3 & 9 \\
\hline keep up with the Joneses & - & 2 & - & - & 6 & 8 \\
\hline fiddle while Rome burns & - & - & 1 & 2 & 4 & 7 \\
\hline meet one's Waterloo & 1 & 1 & 2 & - & 3 & 7 \\
\hline (pile/heap) Pelion on Ossa & - & 3 & - & - & 2 & 5 \\
\hline paint the Forth Bridge & - & 1 & - & - & 3 & 4 \\
\hline (live) the life of Riley & 1 & 2 & - & - & - & 3 \\
\hline appeal to Caesar & - & - & - & - & 2 & 2 \\
\hline (go to) Davy Jones' locker & - & - & - & - & 2 & 2 \\
\hline raise Cain & - & 1 & - & - & 1 & 2 \\
\hline have kissed the Blarney Stone & - & 1 & - & - & 1 & 2 \\
\hline send someone to Coventry & - & 2 & - & - & - & 2 \\
\hline appeal from Philip drunk to Philip sober & & & & & & 0 \\
\hline give a Roland for an Oliver & & & & & & 0 \\
\hline out-Herod Herod & & & & & & 0 \\
\hline build castles in Spain & & & & & & 0 \\
\hline
\end{tabular}

Table 2. Frequency distribution of idiomatic VPs

\begin{tabular}{|l|c|c|c|c|c|c|}
\hline PP & S & F & N & A & M & Total \\
\hline (not) for all the tea in China & - & 5 & - & - & - & 5 \\
\hline between Scylla and Charybdis & - & 2 & - & 1 & - & 3 \\
\hline on one's Jack & - & - & - & - & 2 & 2 \\
\hline in Queer Street & 1 & - & - & - & - & 1 \\
\hline according to Hoyle & & & & & & 0 \\
\hline in Abraham's bosom & & & & & & 0 \\
\hline from China to Peru & & & & & & 0 \\
\hline
\end{tabular}

Table 3. Frequency distribution of idiomatic PPs 


\begin{tabular}{|l|c|c|c|c|c|c|}
\hline clause & S & F & N & A & M & Total \\
\hline before one/you can say Jack Robinson & - & 5 & - & - & 2 & 7 \\
\hline
\end{tabular}

Table 4. Frequency distribution of subordinate clause

\begin{tabular}{|l|c|c|c|c|c|c|}
\hline binomial & S & F & N & A & M & Total \\
\hline Jekyll and Hyde & 4 & 1 & 3 & 1 & 18 & 27 \\
\hline Darby and Joan & - & 6 & - & - & 9 & 15 \\
\hline David and Goliath & - & 2 & 4 & - & 7 & 13 \\
\hline shipshape and Bristol fashion & - & 1 & - & - & 2 & 3 \\
\hline Damon and Pythias & & & & & & 0 \\
\hline
\end{tabular}

Table 5. Frequency distribution of irreversible binomials

\begin{tabular}{|l|c|c|c|c|c|c|}
\hline simile & S & F & N & A & M & Total \\
\hline pleased as Punch & 2 & 12 & 4 & - & 4 & 22 \\
\hline (grin / smile) like a Cheshire cat & - & 5 & 1 & - & 4 & 10 \\
\hline happy as Larry & - & 1 & 1 & - & 3 & 5 \\
\hline rich as Croesus & - & 2 & - & - & 1 & 3 \\
\hline (be) like the Black Hole of Calcutta & - & 1 & - & - & 1 & 2 \\
\hline (be) like Daniel in the lion's den & - & - & 1 & - & 1 & 2 \\
\hline (be) like Hamlet without the prince & - & - & 1 & - & - & 1 \\
\hline hot as Hades & & & & & & 0 \\
\hline old as Adam & & & & & & 0 \\
\hline poor as Lazarus & & & & & & 0 \\
\hline fight like Kilkenny cats & & & & & & 0 \\
\hline
\end{tabular}

Table 6. Frequency distribution of stereotyped similes

\begin{tabular}{|l|c|c|c|c|c|c|}
\hline formula & S & F & N & A & M & Total \\
\hline (it's) Murphy's law & 1 & 2 & 3 & - & 10 & 16 \\
\hline (and) Bob's your uncle & 3 & 9 & - & - & 1 & 13 \\
\hline for the love of Mike & - & 4 & - & - & - & 4 \\
\hline I'm all right, Jack & - & 1 & - & - & 2 & 3 \\
\hline It was even Steven & - & - & 1 & - & - & 1 \\
\hline all Lombard Street to a China orange & & & & & & 0 \\
\hline
\end{tabular}

Table 7. Frequency distribution of formulae

Examining corpus evidence, the 91 expressions have very low levels of occurrence; 18 have zero occurrence, in particular, the units labelled as 'dated', 'old-fashioned' or 'literary' in dictionaries. Yet, 10 expressions are found to be significantly more frequent than the others: e.g. Achilles heel (51); take the Mickey (49); Aladdin's cave (44); a Pandora's box (37); peeping Tom (29); Jekyll and Hyde (27); Uncle Sam (25); a Frankenstein('s) monster (22); pleased as Punch (22); the Midas touch (21). The case of peeping Tom, more frequent than one might expect, can be explained on the ground that it is the neutral expression for the concept, where voyeur is marked, for example, it is a technical term in psychology. 
As to variation, reduction was observed, in particular, in some idiomatic verb phrases (e.g. open a Pandora's box, carry coals to Newcastle). The expressions are usually shortened when they are familiar to users, hence predictable.

With regard to their distribution across registers, 7 units occur in all registers: 5 are out of the 10 most frequent units (Achilles heel, take the Mickey, Aladdin's cave, peeping Tom, Jekyll and Hyde), 2 have a 'median' level of frequency (sword of Damocles, the man on the Clapham omnibus). Most of the expressions result to be more common in written registers; also formulae, typically used in speech, rarely occur in spoken registers. (We should consider that the written subcorpus is nine times as big as the spoken one). The results of the BNC search seem to confirm what emerges in the corpus-based study by Moon (1998: 309). In written discourse, phraseological units are very rarely found in academic writing; they are more commonly found in fiction, to promote the illusion of oral mode in dialogues, and in journalistic prose and miscellaneous texts. Here, they lend an informal, vivid colour to discourse, and increase solidarity, i. e. they enforce an acknowledgement of common ground between writer and reader, by appealing to shared sociocultural schemas and evaluations (Moon 1998: 267).

\section{$7 \quad$ Conclusion}

Some points emerge from the analysis. First, the largest group of expressions is constituted by idioms having the structure of noun phrases. Secondly, the personal and place names involved in phraseology are historically, socially or culturally prominent in British culture. Among them, there is a predominance of personal over place names, and within the former, a predominance of male over female names, and first names over family names, with a number of hypocorisms. Thirdly, many units express evaluation (often disapproval or criticism).

With regard to the corpus search, the collected units result to be not common in discourse, even if they are widely known by users. For example, we can note the rarity of before you can say Jack Robinson or Judas kiss in use, but as highlighted by Fernando (1996: 219-20), the functional value of an expression cannot necessarily be judged by its rarity in general use. The expressions examined constitute a rich repertoire of resources potentially available to users, who can select the most appropriate expression according to their communicative needs: for example, to add humour, to emphasise an idea, to express a negative evaluation indirectly.

As to distribution across registers, the search has shown that only 7 occur in all registers; most expressions are more commonly used in written registers, in particular, in fiction, journalism and miscellaneous texts.

The present study has provided a starting point, and further research can make the picture of phraseology involving PNs more accurate and complete. For example, future studies can use other corpora to verify the extent to which the tendencies and distributions observed in the $\mathrm{BNC}$ are borne out, or to explore cultural differences between national varieties of English.

\section{References}

Allerton, Derek J. (1987): "The Linguistic and Sociolinguistic Status of Proper Names". Journal of Pragmatics 11: 61-92.

Anderson, John M. (2003): "On the Structure of Names". Folia Linguistica 37: 347-398.

Anderson, John M. (2007): The Grammar of Names. Oxford.

Carroll, John M. (1983): "Toward a Functional Theory of Names and Naming". Linguistics 21: 341-71.

Coates, Richard (2006): "Properhood". Language 82: 356-82. 
Cowie, Anthony Paul (1998): "Introduction". In: Cowie, Anthony Paul (ed.): Phraseology. Theory, Analysis and Applications. Oxford: 1-20.

Fernando, Chitra (1996): Idioms and Idiomaticity. Oxford.

Gary-Prieur, Marie-Noëlle (1991): "Le nom propre constitue-t-il une categorie linguistique?" Langue Française 92: 4-25.

Gläser, Rosamarie (1998): "The Stylistic Potential of Phraseological Units in the Light of Genre Analysis". In: Cowie, Anthony Paul (ed.): Phraseology. Theory, Analysis and Applications. Oxford: 125-143.

Grant, Lynn (2005): "Frequency of 'core idiom' in the British National Corpus (BNC)". International Journal of Corpus Linguistics 10/4: 429-451.

Hockett, Charles F. (1958): A Course in Modern Linguistics. New York.

Hough, Carole (2000): "Towards an Explanation of Phonetic Differentiation in Masculine and Feminine Personal Names". Journal of Linguistics 36: 1-11.

Kripke, Saul (1972): "Naming and Necessity". In: Davidson, Donald/Harman, Gilbert (eds.): Semantics of Natural Language. Dordrecht/Boston: 253-355.

Lehrer, Adrienne (1994): "Proper Names. Linguistic Aspects". In: Asher R. E. (ed.): The Encyclopaedia of Language and Linguistics. Vol. 6. Oxford: 3372-3374.

Lyons, John (1977): Semantics. Vol. 1. Cambridge.

Marmaridou, A. Sophia S. (1989): "Proper Names in Communication". Journal of Linguistics 25: 355-372.

Mill, John S. (1867): A System of Logic. New York. Available at: http://books.google.it/ books?id=E9CupFDGDRwC\&printsec=frontcover\&dq=A+system+of+logic\#PPR1.M1 (accessed September 2007).

Molino, Jean (1982): "Le nom propre dans la langue". Langages 66: 5-20.

Moon, Rosamund (1998): Fixed Expressions and Idioms in English. A Corpus-based Approach. Oxford.

Pierini, Patrizia (2006): "Antroponimi inglesi e traduzione". In: D'Achille, Paolo/Caffarelli, Enzo (ed.): Lessicografia e onomastica: 225-240. (= Quaderni Internazionali di RIOn (Rivista Italiana di Onomastica) 2).

Searle, John R. (1975): "A Taxonomy of Illocutionary Acts". In: Gunderson, Keith (ed.): Language, Mind and Knowledge. Minneapolis: 344-369.

Sloat, Clarence (1969): "Proper Nouns in English". Language 45: 26-30.

Teliya, Veronika et al. (1998): "Phraseology as a Language of Culture. Its Role in the Representation of a Cultural Mentality". In: Cowie, Anthony Paul (ed.): Phraseology. Theory, Analysis and Applications. Oxford: 55-75.

Tse, Grace Y. W. (2004): "A Grammatical Study of Personal Names in Present-day English. With Special Reference to the Usage of the Definite Article". English Studies 3: 241-259.

Van Langendonck, Willy (2007): Theory and Typology of Proper Names. Berlin.

Wee, Lionel (2006): "Proper Names and the Theory of Metaphor". Journal of Linguistics 42/2: 355-371.

\section{Dictionaries}

CED = Collins English Dictionary (2000). Glasgow: HarperCollins Publishers.

CCDI = Collins COBUILD Dictionary of Idioms (1995). London: HarperCollins Publishers.

LDEI = Longman Dictionary of English Idioms (1980). London: Longman.

LID = Longman Idioms Dictionary (1998). London: Longman.

ODI = Oxford Dictionary of Idioms (2000). Oxford: Oxford University Press. 


\section{Corpus}

The British National Corpus. Available at http://corpus.byu.edu/BNC (last accessed on 22 January 2008). 